\title{
The neutrophil-recruiting chemokine GCP-2/CXCL6 is expressed in cystic fibrosis airways and retains its functional properties after binding to extracellular DNA
}

\author{
S Jovic ${ }^{1}$, HM Linge ${ }^{1}$, MM Shikhagaie ${ }^{1}$, AI Olin $^{2}$, L Lannefors $^{1}$, JS Erjefält ${ }^{1}$, M Mörgelin ${ }^{2}$ and A Egesten $^{1}$
}

Infections in cystic fibrosis (CF), often involving Pseudomonas aeruginosa, result from a dysregulated airway immunity where one hallmark is the accumulation of necrotic and apoptotic immune cells, in particular neutrophils. In addition, neutrophils actively release DNA, forming neutrophil extracellular traps (NETs) that contain antimicrobial proteins.

Altogether, free DNA in complex with actin accumulates in the airway lumen, resulting in highly viscous sputum that provides an anionic matrix, binding cationic antimicrobial proteins. In this study, granulocyte chemotactic protein 2 (GCP-2)/CXCL6, a neutrophil-activating chemokine with bactericidal properties, was detected in the airway epithelium of CF patients and was also present in azurophilic and specific granules of neutrophils. Elastase of neutrophils, but not of $P$. aeruginosa, completely degraded CXCL6 (chemokine (C-X-C motif) ligand 6). In addition, CXCL6 colocalized with extracellular DNA in both CF sputa and in in vitro-formed NETs. In vitro, CXCL6 bound DNA with a $K_{\mathrm{D}}$ of $2,500 \mathrm{nM}$. Interestingly, both the bactericidal and the receptor-activating properties of CXCL6 (against neutrophils) remained largely unaffected in the presence of DNA. However, the chemotactic properties of CXCL6 were reduced by the presence of DNA. Taken together, CXCL6 is expressed in CF, retaining its functional properties even after binding to the anionic scaffold that extracellular DNA provides in CF.

\section{INTRODUCTION}

The genetic defect of the chloride channel cystic fibrosis transmembrane conductance regulator (CFTR) in cystic fibrosis (CF) results in dysfunctions of several organs. Major clinical challenges include the airways where viscous sputum, chronic bacterial infections, and inflammation present problems. One of the most important pathogens is the Gram-negative pathogen Pseudomonas aeruginosa that, once established in the airways, promotes the progress of the disease. ${ }^{1}$ The impaired airway immunity may be attributed to altered properties of the periciliary liquid that is part of the airway surface liquid on the apical side of airway epithelial cells. ${ }^{2}$ An increased chloride concentration of the periciliary liquid has been suggested, but more recently an alternative explanation, demonstrating a reduced $\mathrm{pH}$, was shown in a porcine model of
$\mathrm{CF}^{3-6}$ In addition, highly viscous sputum presents a clinical problem in itself but may also be part of the vulnerability to acquire infections. ${ }^{7,8}$ Factors that may affect the properties of sputum are altered production of mucins and a high abundance of free DNA in complex with actin. ${ }^{9-11}$ The DNA originates from immune cells, in particular neutrophils that accumulate in the airways of CF patients. ${ }^{12}$ Several possible mechanisms can explain the high number of neutrophils including delayed apoptosis and a defect in the removal of apoptotic cells. ${ }^{13-18} \mathrm{In}$ addition, neutrophils can actively release their nuclear DNA as a mode of antimicrobial defense, i.e., neutrophil extracellular traps (NETs), a mechanism that is upregulated in the airways of CF patients. ${ }^{18,19}$ Proteins with antibacterial properties originating from the nucleus (histones), the cytosol (i.e., S100A8 and S100A9), and preformed granule proteins with antibacterial

${ }^{1}$ Division of Respiratory Medicine and Allergology, Department of Clinical Sciences Lund, Lund University, Lund, Sweden and ${ }^{2}$ Division of Infection Medicine, Department of Clinical Sciences Lund, Lund University, Lund, Sweden. Correspondence: S Jovic (sandra.jovic@med.lu.se) 
properties (e.g., myeloperoxidase (MPO), the serine proteases elastase, proteinase 3, cathepsin G, azurocidin, lactoferrin, and lysozyme) are found immobilized in NETs where they may exert antimicrobial activity. ${ }^{20}$

Granulocyte chemotactic protein 2 (GCP-2/CXCL6) is a neutrophil-recruiting ELR + chemokine that signals through the receptors CXCR1 and CXCR2 that are expressed on neutrophils. ${ }^{21-23}$ Several chemokines have direct antibacterial activity. ${ }^{24}$ We have previously demonstrated bactericidal activity of CXCL6 (chemokine (C-X-C motif) ligand 6) against both Gram-positive and Gram-negative pathogens, including $P$. aeruginosa. ${ }^{25}$

In this study, we show that CXCL6 is expressed in CF airways and it is also present in cytoplasmic granules of neutrophils. In addition, it is bound to extracellular DNA in CF sputum, experimentally generated NETs, and when bound to DNA, CXCL6 retains its receptor-activating activity and bactericidal activity whereas the chemotactic properties are reduced.

\section{RESULTS}

\section{Detection of CXCL6 in CF lung tissue by} immunohistochemistry

CXCL6 was detected by immunohistochemistry in lung tissue obtained from five patients suffering from end-stage CF and undergoing transplantation. As controls, lung tissue from eight previously lung healthy, never-smoking individuals, undergoing surgery for lung cancer was used. In never-smoker control subjects, no CXCL6 was detected (Figure 1a), whereas in lung tissue from end-stage CF patients the chemokine was detected mainly in goblet cells of the airway epithelium (Figure 1 $\mathbf{1 b}, \mathbf{c}$ ). In addition, CXCL6 was detected in submucosal cells of the small airways (Figure 1d) where double immunostaining with MPO confirmed that the vast majority of these cells were neutrophils (Figure 1e). The distribution of various forms of DNA in $\mathrm{CF}$ airways was visualized using Hoechst stain (a marker of doublestranded DNA), TUNEL (terminal deoxynucleotidyl transferase dUTP nick end labeling; recognizing DNA subjected to cleavage during apoptosis), and MPO that were applied on the same tissue sections and investigated using double fluorescence microscopy (Figure 1f). Neutrophils were seen in the submucosa and within the epithelium where other cells (i.e., lacking MPO) appeared $\mathrm{TUNEL}^{+}$. In the lumen, high presence of apoptotic neutrophils and other apoptotic cells was seen.

\section{Detection of CXCL6 on an ultrastructural level}

Ultrathin sections of CF airways were examined by transmission electron microscopy (TEM). Cellular debris, necrotic cells, and sputum were visible within the airway lumen (Figure 2a). In the sputum-rich areas, CXCL6 was detected by immunogoldlabeled antibodies (Figure 2b). Similarly, CXCL6 was detected by immunogold in sputum mobilized from the airways of $\mathrm{CF}$ patients (Figure 2c). In necrotic neutrophils of CF airways (arrows in Figure 2a), CXCL6 was detected in cytoplasmic granules and redistributed to the cytoplasm as well as in large vacuoles of the cytoplasm (Figure 2d,e). To determine the subcellular location of CXCL6, neutrophils from healthy individuals were double stained with gold-labeled antibodies against either bactericidal/permeability-increasing protein (BPI), a marker of azurophilic granules (Figure 2f), or hCAP-18 (Figure 2g), a marker of specific granules. The results show that CXCL6 is localized to both these compartments in resting neutrophils of healthy individuals. In lysates of purified neutrophils (>96\%), the CXCL6 content was $0.4 \pm 0.07 \mathrm{ng}$ (mean \pm s.d.; $n=4$ ) per $10^{6}$ cells as determined by enzymelinked immunosorbent assay. In CF sputum, the CXCL6 and LL37 content was $\sim 1$ and $35 \mathrm{ng} \mathrm{ml}^{-1}$, respectively, as measured by enzyme-linked immunosorbent assay $(n=23$, range $0.04-4.32$ and $6.2-78.6 \mathrm{ng} \mathrm{ml}^{-1}$, respectively).

\section{Bactericidal activity of CXCL6 against $\boldsymbol{P}$. aeruginosa}

To study the influence from sodium chloride and $\mathrm{pH}$, viable counts assays were performed, employing the $P$. aeruginosa strain PA01 and the clinical nonmucoid CF strains (195b, 022A, and 032). CXCL6 $(1 \mu \mathrm{M})$ showed bactericidal activity against $P$. aeruginosa (PA01) in the order of the antibacterial peptide LL$37(1 \mu \mathrm{m})$ in the absence and presence of 80 and $140 \mathrm{~mm}$ sodium chloride at a $\mathrm{pH}$ of 7.5 (Figure $3 \mathrm{a}$ ). Lowering the $\mathrm{pH}$ from 7.5 to 7.0 in the presence of $140 \mathrm{~mm}$ sodium chloride had no significant effect on the bactericidal activity of both CXCL6 $(1 \mu \mathrm{M})$ and LL-37 $(1 \mu \mathrm{M})$ against $P$. aeruginosa (PA01) (Figure 3b). Possible additive or synergistic effect of CXCL6 and LL-37 in terms of antimicrobial activity was investigated by combining CXCL6 and LL-37 in a viable count assay against $P$. aeruginosa (PA01) at $\mathrm{pH} 7.4$ and $140 \mathrm{~mm}$ sodium chloride. A weak additive effect was observed combining CXCL6 and LL-37 at a concentration of $0.3 \mu \mathrm{M}$ (Figure 3c). The killing activity of $P$. aeruginosa (PA01) and the clinical nonmucoid CF strains (195b, 022A, and 032) by CXCL6 at pH 7.5 and $140 \mathrm{~mm}$ sodium chloride was similar (Figure 3d).

\section{Proteolytic processing of CXCL6 by elastases}

Possible degradation of CXCL6 by elastase of neutrophils and $P$. aeruginosa was compared with the prototypic ELR + chemokine interleukin (IL)-8/CXCL8 and the ELR - chemokine MIG/CXCL9. Recombinant human CXCL6, CXCL8, and CXCL9 were incubated with neutrophil elastase and $P$. aeruginosa elastase for 3 and $18 \mathrm{~h}$ at $37^{\circ} \mathrm{C}$ followed by separation on Tris-tricine gels and stained with Coomassie Brilliant Blue R-350 (Figure 4). Neutrophil elastase completely degraded CXCL6 after $3 \mathrm{~h}$, whereas CXCL8 was partly degraded after $3 \mathrm{~h}$ and completely degraded after $18 \mathrm{~h}$. CXCL9 was processed to a smaller fragment after $18 \mathrm{~h}$ of incubation, as previously reported. ${ }^{26}$ In contrast, $P$. aeruginosa elastase did degrade neither CXCL6 nor CXCL8, whereas CXCL9 was processed (Figure 4a). To investigate whether DNA could affect the sensitivity of CXCL6 and CXCL8 to proteolytic degradation by neutrophil elastase, CXCL6 and CXCL8 were preincubated with DNA before incubation with neutrophil elastase for $18 \mathrm{~h}$. Addition of DNA did not inhibit the degradation of CXCL6 (Figure 4b). In a western blot, CXCL6 was observed in neutrophil lysates and in NETs. However, addition of exogenous CXCL6 to the NETs resulted 

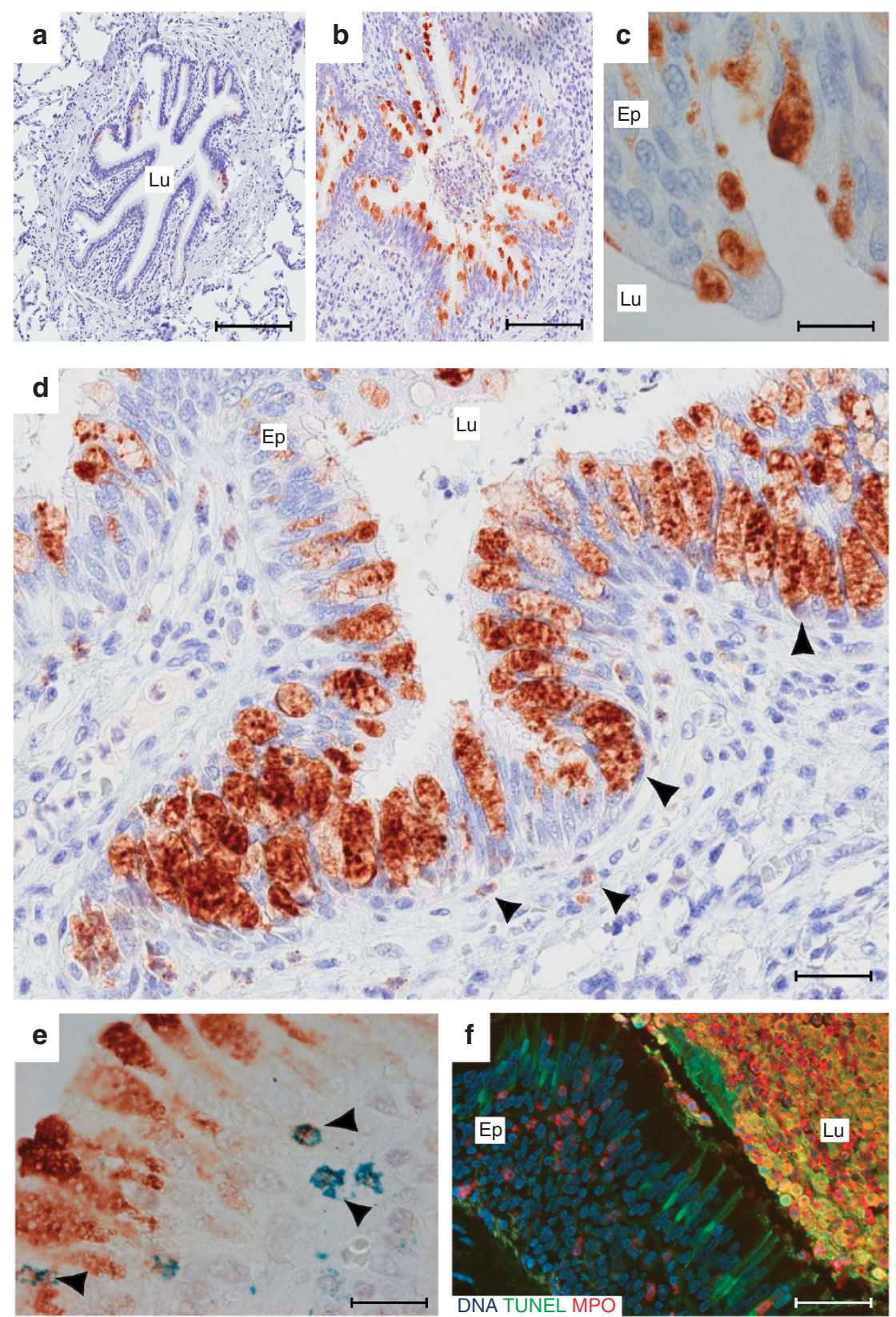

Figure 1 Detection of CXCL6 (chemokine (C-X-C motif) ligand 6) and DNA in small airways. Representative micrographs from (a) a never-smoker control subject and (b) a patient with cystic fibrosis (CF) stained to detect CXCL6-expressing cells in the airways (primary antibodies are visualized by peroxidase-conjugated secondary antibodies reacting with DAB resulting in a brown stain). (a) In control subjects no CXCL6 is detected, (b) whereas in small airways of CF patients CXCL6 is seen in the epithelium. No CXCL6 is detected in the alveoli. CXCL6 is seen in goblet cells of the epithelium (arrows) and in granulocytes beneath the epithelium (c,d; arrowheads). Double labeling confirms that the majority of the intra- and sub-epithelial CXCL6containing (brown stain) cells are neutrophils, being positive for myeloperoxidase (MPO; green stain). (e) Double-positive cells are indicated by arrowheads. Immunofluorescent staining showing presence of neutrophils in association with airway epithelium and in the airway lumen together with DNA, both of intact and apoptotic cells in CF airway. MPO-containing neutrophils (red stain) are seen both in the lumen, sub- and intra-epithelially. (f) TUNEL (terminal deoxynucleotidyl transferase dUTP nick end labeling)-positive apoptotic cells (green stain) and cell nuclei stained with DNA marker Hoechst (blue stain) are well separated in association with the airway epithelium, whereas there is a compact mixture in the airway lumen together with an abundant presence of neutrophils. Scale bars: $(\mathbf{a}, \mathbf{b}, \mathbf{f}) 100 \mu \mathrm{m}$; (c-e) $50 \mu \mathrm{m}$. Ep, small airway epithelium; Lu, small airway lumen.

in a stronger immune-reactive band in the western blot, indicating binding of added CXCL6 to the NETs (Figure 4c).

\section{CXCL6 has DNA-binding properties}

To investigate a possible localization of CXCL6 in NETs, neutrophils purified from peripheral blood of healthy donors were activated with glucose oxidase and the resulting NETs were investigated using negative staining and immunoelectron microscopy. CXCL6, labeled with colloidal gold, was seen associated with DNA (Figure 5a). In sputa from three individual CF patients, CXCL6 was similarly associated with DNA (Figure 5b-d). To investigate CXCL6 binding to 

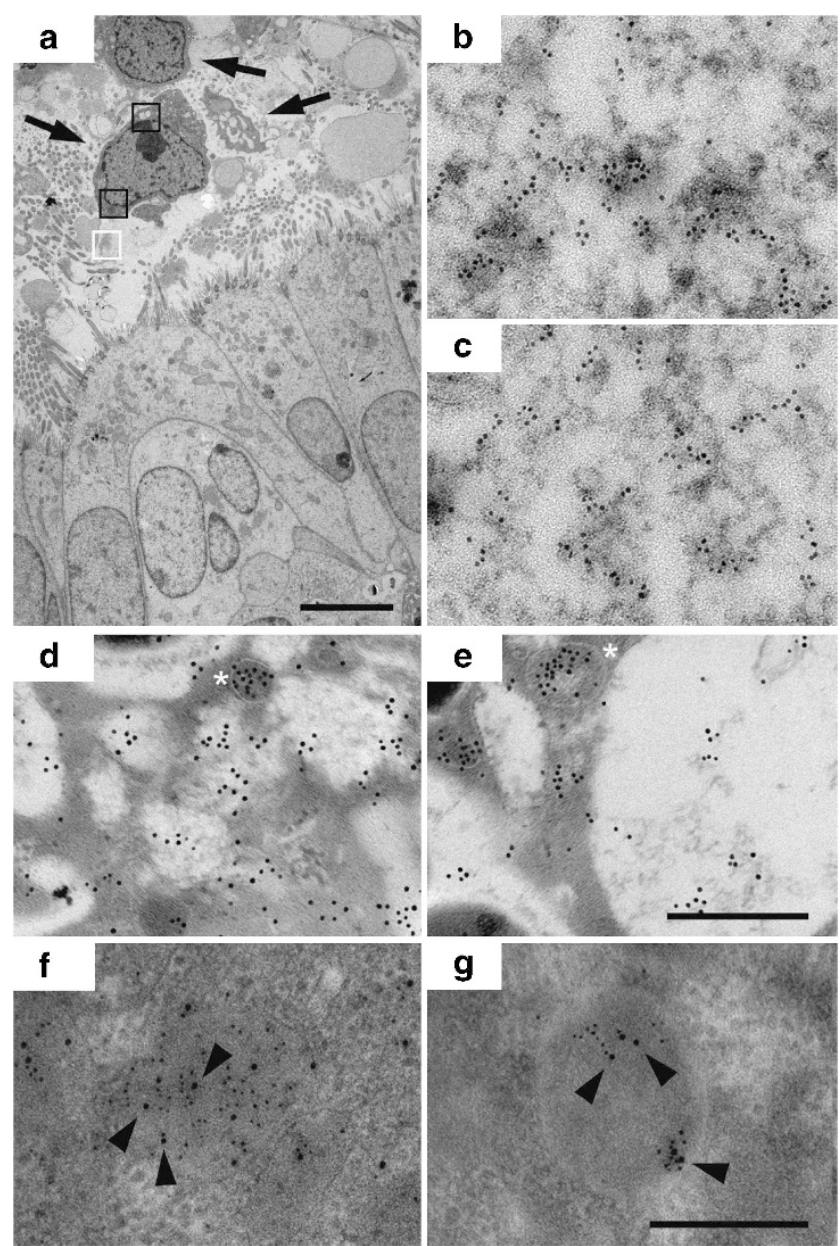

Figure 2 Ultrastructural detection of CXCL6 (chemokine (C-X-C motif) ligand 6). Cystic fibrosis (CF) airways were examined by transmission electron microscopy and an overview is seen in (a) depicting epithelial cells in its lower part and a lumen with necrotic cells (arrows and black boxes), cellular debris (white box), and sputum. An area with sputum is indicated within the lumen (white box). (b) In the marked area, CXCL6 is detected by specific antibodies that are visualized by secondary immunogold-labeled $(5 \mathrm{~nm})$ antibodies. (c) Similarly, in sputum mobilized from the airways of a CF patient, CXCL6 is detected by immunogold. Within the necrotic neutrophils of CF airways (indicated by arrows in a), CXCL6 is both present in granules of the cytoplasm (asterisks in $\mathbf{d}$ and $\mathbf{e}$ ) and redistributed to the cytoplasm, appearing as scattered gold particles. (e) In addition, some presence of CXCL6 is seen in vacuoles of necrotic neutrophils (asterisks). To determine the subcellular localization of CXCL6 in intact neutrophils, cells from healthy individuals were double stained with gold-labeled antibodies against CXCL6 ( $5 \mathrm{~nm}$ gold particles) and bactericidal/permeability-increasing protein (BPI), a marker of azurophilic granules (15 nm gold particles, arrowheads in f), or hCAP-18, a marker of specific granules ( $15 \mathrm{~nm}$ gold particles, arrowheads in $\mathbf{g}$ ). This shows that CXCL6 is present in both azurophilic and specific granules, the staining being more intense in the former compartment. The scale bar in a is $5 \mu \mathrm{m}$, in $\mathbf{e}$ is $0.5 \mu \mathrm{m}$ (b-e have the same magnification), and in $\mathbf{g}$ is $250 \mathrm{~nm}$ (f and g have the same magnification).

DNA in vitro, increasing concentrations of recombinant CXCL6 were incubated with DNA followed by electrophoresis in an agarose gel (electromobility shift; Figure 5e). This demonstrated a dose-dependent inhibition of DNA migration with increasing concentrations of CXCL6, indicating CXCL6 binding to DNA, retarding its movement. Surface plasmon resonance confirmed CXCL6 binding to DNA $\left(K_{\mathrm{D}} 2,500 \mathrm{nM}\right)$ in the presence of sodium chloride (140 mM), mimicking the salt concentrations of periciliary liquid. As references, CXCL8 bound DNA at a $K_{\mathrm{D}}$ of 35,600 nм, whereas CCL3 showed no binding (Figure 5f).

\section{Effects from DNA on the chemotactic and receptor- activating properties of CXCL6}

CXCL6 exerts neutrophil-activating activities through binding CXCR1 and CXCR2. ${ }^{23}$ Purified neutrophils and calciumsensitive fluorescent dyes were used to investigate receptor activation of CXCL6 in the absence and presence of DNA. CXCL6 induced a rapid and dose-dependent calcium response, reaching a maximum at $100 \mathrm{~nm}$. Preincubation of CXCL6 $(1,10$, and $100 \mathrm{~nm}$ ) with DNA (at a final concentration of $200 \mathrm{pm}$ ) resulted in a small but nonsignificant reduction of the calcium mobilization response in neutrophils (Figure 6a). DNA alone did not induce calcium mobilization. As DNA binds to both CXCL6 and CXCL8, we further investigated whether DNA binding to the chemokines could affect their chemotactic properties against neutrophils. A typical bell-shaped doseresponse curve was obtained when using concentrations from 1 to $100 \mathrm{~nm}$ of the chemokines (Figure $\mathbf{6 b}$ ). Preincubation of CXCL6 or CXCL8 (both at $10 \mathrm{~nm}$ ) with DNA (200 pM) before adding the neutrophils significantly reduced the chemotactic properties of both chemokines (Figure 6c).

\section{DNA does not interfere with the antibacterial properties of CXCL6}

Fluorescent dyes (Syto 9 staining all bacteria and propidium iodide binding intracellular DNA in killed bacteria) were used to assess bacterial viability. CXCL6 $(12.6 \mu \mathrm{M})$ resulted in bacterial killing, visualized as red/yellow fluorescence from internalized dyes in permeabilized bacteria (Figure 7a). CXCL6 $(12.6 \mu \mathrm{M})$ preincubated with DNA $(25.2 \mathrm{nM})$ retained its bactericidal activity, whereas bacteria in buffer alone or incubated with DNA remained intact. Viable counts were performed to confirm the results. No differences were observed in the killing of $P$. aeruginosa with CXCL6 alone or when preincubated with DNA. Addition of DNAse to release bacteria potentially trapped in the DNA did not affect the results (Figure $7 \mathbf{b}$ ). Recently, it was shown that the DNA of NETs possess antimicrobial activity against $P$. aeruginosa (PA01). ${ }^{27}$ This may explain why the addition of CXCL6 to NETs does not increase the antibacterial activity against these bacteria (Figure 7c).

\section{DISCUSSION}

In this study, we show that CXCL6 is produced by the airway epithelium of the large airways in CF. In addition, this chemokine is present as a preformed protein in azurophilic and specific granules of neutrophils. In CF sputa, we found CXCL6 associated with extracellular DNA that was paralleled by binding to DNA of experimentally generated NETs. When bound to DNA, CXCL6 retained its receptor-activating and bactericidal activity whereas the chemotactic properties were decreased. To our knowledge, this is the first demonstration of extracellular DNA providing an anionic scaffold that binds a chemokine, the latter retaining most of its functional properties. 

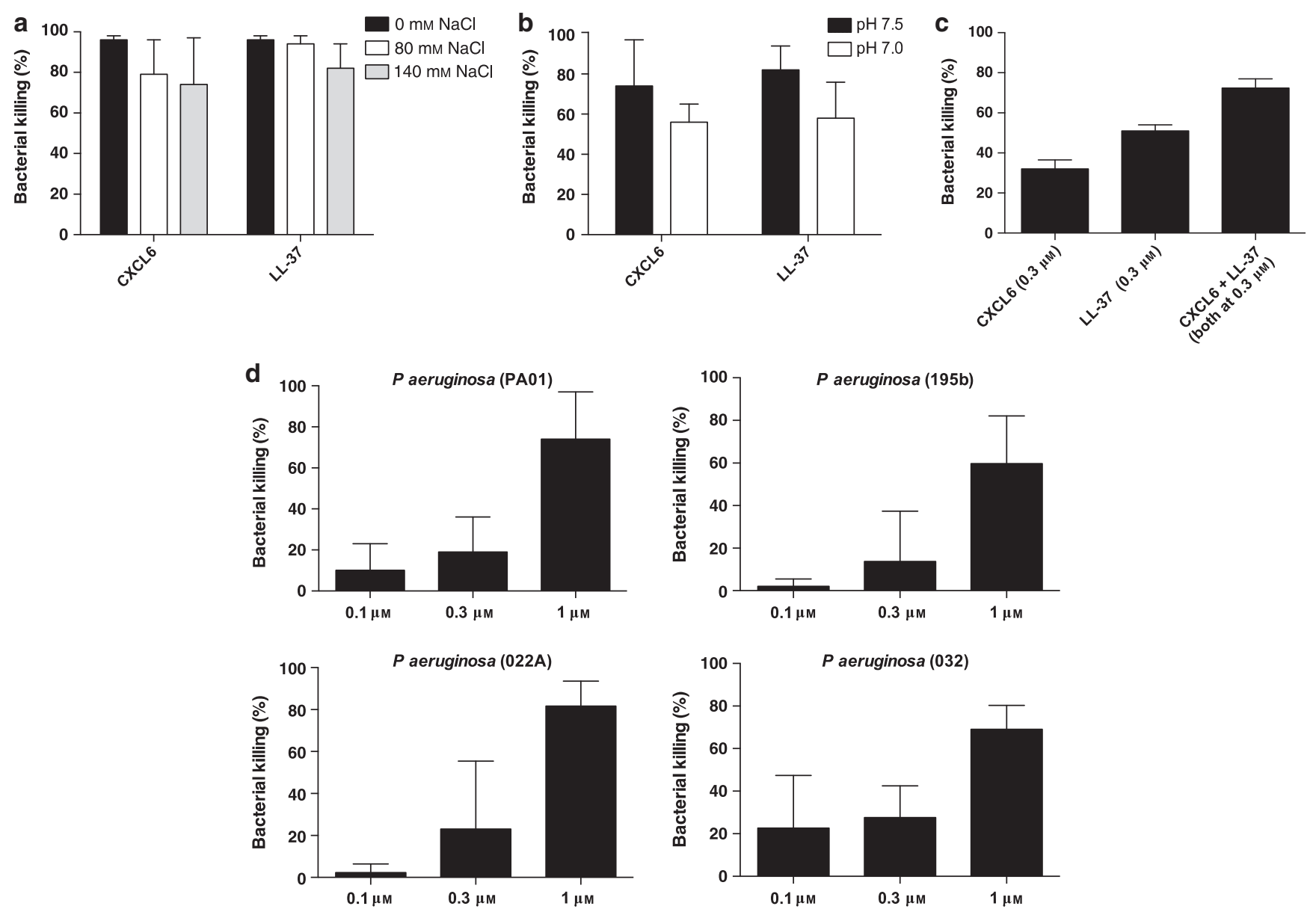

Figure 3 Bactericidal activity of CXCL6 (chemokine (C-X-C motif) ligand 6) and LL-37 against Pseudomonas aeruginosa. To investigate whether the altered microenvironment of the periciliary liquid (PCL) in cystic fibrosis (CF) affects the bactericidal activity of CXCL6 and LL-37, different salt concentrations and $\mathrm{pH}$ were used in the viable counts assay against $P$. aeruginosa PA01. (a) The bactericidal activity of CXCL6 and LL-37 (both at $1 \mu \mathrm{M}$ ) in the absence and presence of 80 and $140 \mathrm{~mm}$ sodium chloride at pH 7.5. (b) The bactericidal activity of CXCL6 and LL-37 (both at $1 \mu \mathrm{m}$ ) in the presence of $140 \mathrm{~mm}$ sodium chloride and $\mathrm{pH} 7.5$ or 7.0. (c) A weak additive effect of CXCL6 and LL-37 in terms of antibacterial activity against $P$. aeruginosa PA01 was observed. (d) Dose-dependent killing of $P$. aeruginosa PA01 and the clinical nonmucoid CF strains (195b, 022A, and 032) of CXCL6 at pH 7.5 and $140 \mathrm{~mm}$ sodium chloride. The data represent mean and s.d. of three to five separate experiments. No significant decrease in bactericidal activity of CXCL6 or LL37 was observed when comparing the bactericidal activity in different salt concentrations and $\mathrm{pH}$.

Several cytokines are likely to promote the expression of CXCL6 in the airways during CF. Both IL-1 $\beta$ and IL-17, cytokines that are expressed in $\mathrm{CF}$ airways, induce expression of CXCL6 in bronchial epithelial cells. ${ }^{28-31}$ IL-23 expression is increased in $\mathrm{CF}$, both in stable disease and during exacerbations, and promotes subsequent expression of IL-17, and T helper type $17 \mathrm{~T}$ cells are among the earliest drivers of the inflammatory response in $\mathrm{CF}^{32,33}$ In addition, IL-17-expressing neutrophils have been identified in CF airways. ${ }^{34}$ Thus, CXCL6 adds to other ELR-positive CXC chemokines such as IL-8/CXCL8 that promote the influx of neutrophils to the airways in $\mathrm{CF} .{ }^{35}$ To explain the presence in neutrophil granules, CXCL6 production has to take place in the bone marrow. This is supported by complementary DNA analysis of gene expression during different stages of neutrophil maturation where the CXCL6 gene was expressed during all stages of neutrophil maturation in the bone marrow. ${ }^{36}$ The sequential formation of the different subsets of neutrophil granules explains the presence of this chemokine in both azurophilic (primary) and specific (secondary) granules. However, it cannot be excluded that CXCL6 is internalized from the extracellular environment at sites of inflammation as neutrophils contain plasma proteins and can exhibit pinocytosis at sites of inflammation. ${ }^{37,38}$

The most well-known effect of CXCL6 is the recruitment of neutrophils via binding to the receptors CXCR1 and CXCR2. ${ }^{22}$ In addition, many chemokines serve as growth factors, and recently CXCL6 neutralization using antibodies resulted in prevention of lung inflammation and remodeling in mice using a bleomycin model. ${ }^{39}$ Other ELR-positive CXC chemokines capable of recruiting neutrophils are expressed in CF airways, among them CXCL8 and CXCL5 ${ }^{40,41}$ where the latter has been shown to exert a weak antibacterial activity. ${ }^{25}$ In addition to CXCL6, mature neutrophils can express several other cytokines and chemokines. Tissue neutrophils activate a transcriptional program that results in generation of several chemokines, 
a
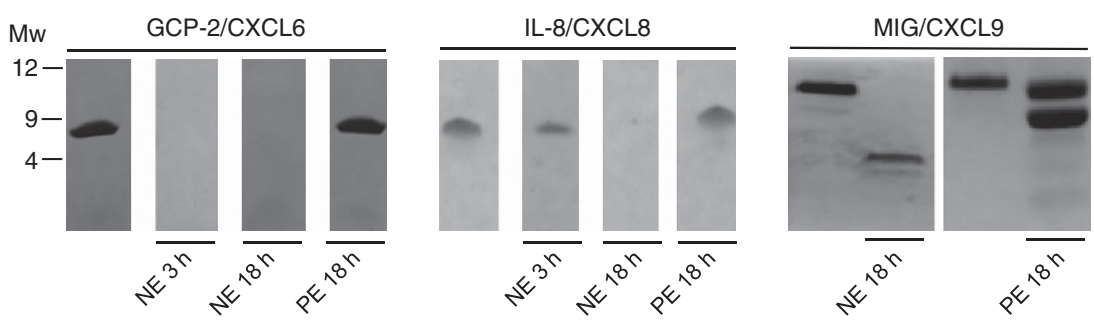

b

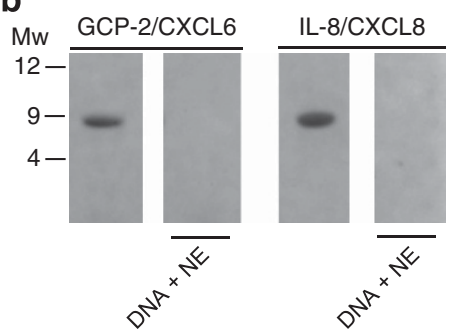

c

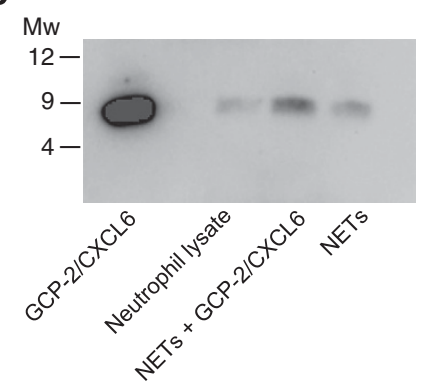

Figure 4 CXCL6 (chemokine (C-X-C motif) ligand 6) is not processed by Pseudomonas aeruginosa elastase. (a) Processing of CXCL6, CXCL8, and CXCL9 by neutrophil elastase (NE) and elastase of $P$. aeruginosa (PE) in vitro. PE did not cleave CXCL6 or CXCL8, but PE processed CXCL9. NE completely degraded CXCL6 after $3 \mathrm{~h}$ and CXCL8 was partly degraded after $3 \mathrm{~h}$ and completely degraded after $18 \mathrm{~h}$, whereas CXCL9 was processed to a smaller fragment after $18 \mathrm{~h}$. (b) CXCL6 and CXCL8 were preincubated with DNA to investigate whether DNA could affect the sensitivity of CXCL6 and CXCL8 to proteolytic degradation by neutrophil elastase. No inhibition of the degradation was observed. (c) In a western blot, CXCL6 was detected in neutrophil lysates and in neutrophil extracellular traps (NETs). A stronger immune-reactive band is observed when exogenous CXCL6 is added to the NETs, indicating binding of CXCL6 to the NETs.

including CXCL8 and CXCL1, resulting in recruitment of additional inflammatory cells. ${ }^{36,42}$

Apart from an increased expression of ELR + CXC chemokines, several additional factors contribute to the excessive accumulation of neutrophils in CF airways. These include prolonged survival of neutrophils from patients with $\Delta \mathrm{F} 508$ CFTR mutations, impaired efferocytosis (i.e., phagocytic removal of dead cells) caused by pyocyanin released by P. aeruginosa, as well as excessive tissue destruction because of high concentrations of proteolytic enzymes that expose danger signals. ${ }^{13-15,17}$

The largely intact receptor-activating activity of CXCL6 when bound to DNA parallels previous findings that chemokines mediate haptotaxis when bound to the anionic matrices provided by glycosaminoglycans. ${ }^{43,44}$ Cell surface glycosaminoglycans promote polymerization of chemokines, increasing their local concentration and therefore enhancing their effects on high-affinity receptors within the local microenvironment. ${ }^{45}$ This may also be the case for CXCL6 in the presence of DNA.

The antibacterial activity of CXCL6 was previously demonstrated to decrease in the presence of salt. ${ }^{25}$ However, the lowering of $\mathrm{pH}$ to mimic the periciliary liquid in $\mathrm{CF}$ in this study produced unclear results. This is in contrast to our recent finding that the antibacterial growth factor midkine exerts lower bacterial activity against $P$. aeruginosa in the presence of salt and at a lower $\mathrm{pH}$, likely because of bacterial membrane protonation and electrostatic shielding respectively. ${ }^{46}$

Entrapment of bacteria in NETs is regarded as an established host defense mechanism, but their bactericidal properties are still questioned. ${ }^{47}$ The findings of this study do suggest that at least some antimicrobial proteins can exert bactericidal activity when also bound to DNA. In vivo, it has been shown that NETs have a complex composition, including histones and membrane vesicles. ${ }^{19}$ Therefore, it is difficult to assess the contribution of CXCL6 on the total antibacterial capacity of NETs. Nonetheless, it is a well-known feature of the immune system to employ multiple, often redundant, mechanisms in its performance.

In patients with CF, sputum is characterized by infiltration with neutrophils and high concentrations of neutrophilderived DNA and filamentous actin. ${ }^{7}$ Therapies that target DNA polymers (deoxyribonuclease) and F-filamentous actin polymers (thymosin $\beta 4$ ) may decrease CF sputum viscoelasticity and improve pulmonary function. ${ }^{48,49}$ How such therapies influence the bioavailability of antibacterial factors like CXCL6 in the extracellular milieu of the CF lung remains to be investigated.

Taken together, the abundance of free DNA in CF airways is likely to contribute to the dysregulated inflammation and vulnerability to infection. Several efforts targeting DNA and its polymers as clinical intervention in CF have shown promising results. ${ }^{10,50}$ The results of this study point to the paradoxical imbalance between neutrophil recruitment to the inflamed airways of CF patients and their lines of antibacterial defense.

\section{METHODS}

Special reagents. Recombinant human CXCL6, CXCL8 (77 amino acid residues), CXCL9 pre-immune IgG, and affinity-purified antibodies against CXCL6 were purchased from Peprotech (Oxford, UK). The CXCL6 enzyme-linked immunosorbent assay was from R\&D 

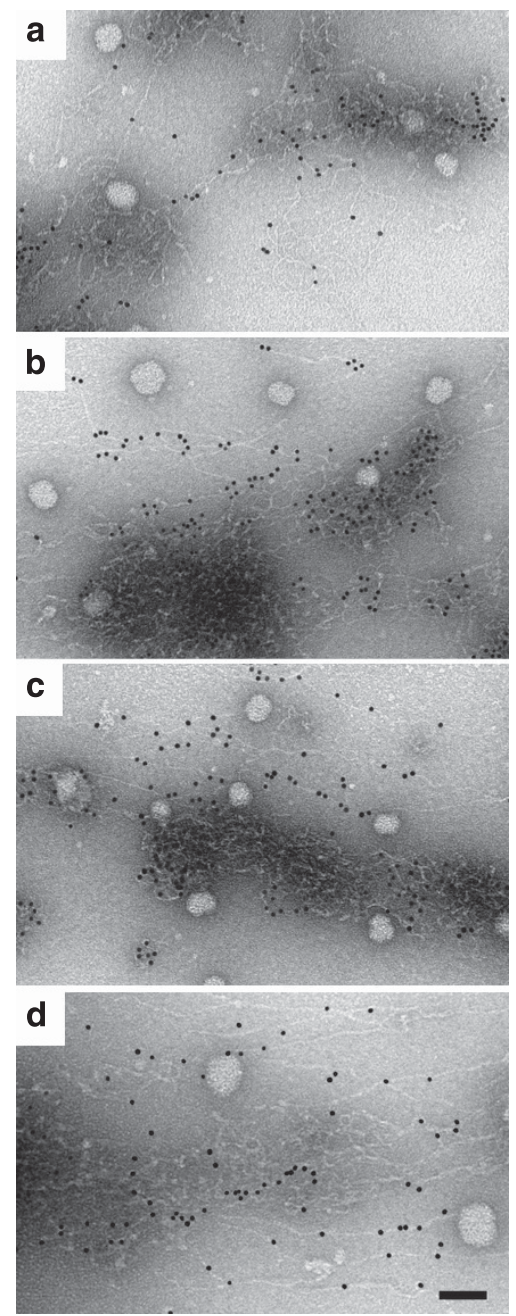

e
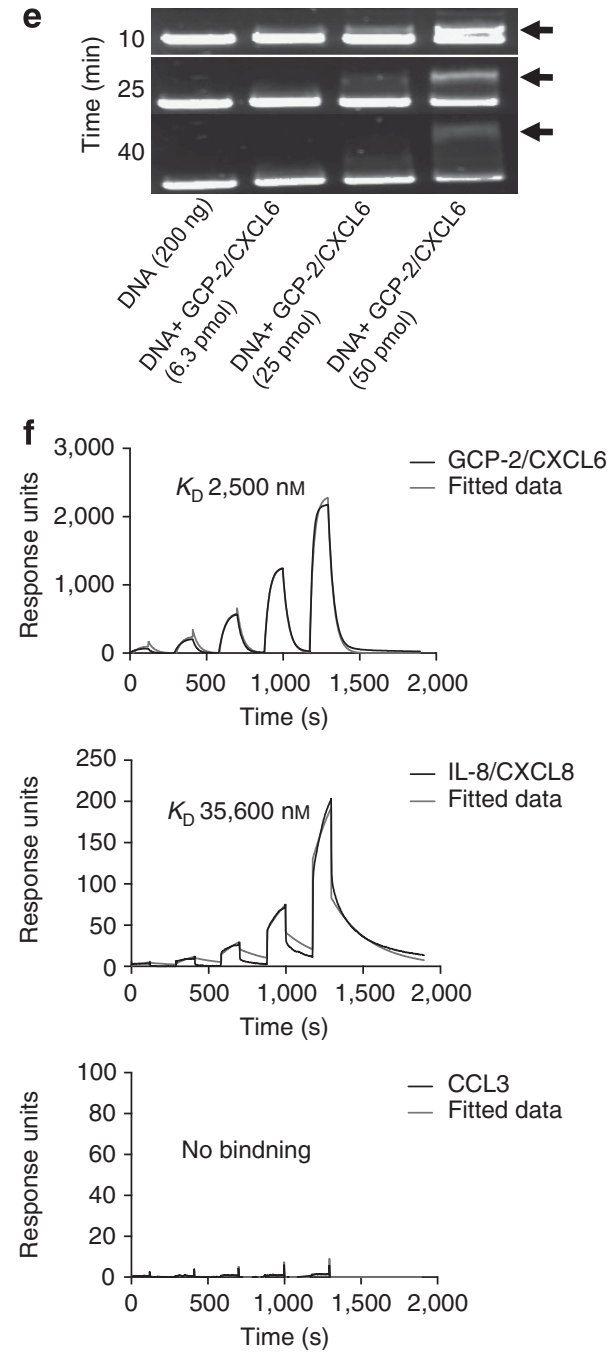

Figure 5 CXCL6 (chemokine (C-X-C motif) ligand 6) has DNA-binding properties. (a) Neutrophils from healthy donors were stimulated to release neutrophil extracellular traps (NETs) by stimulation with glucose oxidase. The DNA is seen as thin fibrils after negative staining and electron microscopy. CXCL6 was visualized by primary antibodies detected by secondary gold-conjugated antibodies (10 nm colloidal gold particles). CXCL6 appearing as gold particles is seen associated with the DNA. One representative out of three separate experiments is shown. (b-d) In sputa from three individuals suffering from cystic fibrosis (CF), DNA and CXCL6 are visualized after negative staining, immunolabeling, and electron microscopy. In a similar manner, CXCL6 (detected by $10 \mathrm{~nm}$ immunogold staining) is associated with stretches of DNA appearing as thin fibrils. Scale bar $=100 \mathrm{~nm}$. (e) CXCL6 binding to DNA is shown by electrophoretic mobility shift assay. One representative image out of two separate experiments is shown. (f) Surface plasmon resonance analysis of CXCL6, CXCL8, and CCL3 (an anionic chemokine) binding to DNA in the presence of 140 mm sodium chloride concentration and a $\mathrm{pH}$ 7.5. The concentration range used was $62.5-1,000 \mathrm{~nm}$.

Systems (Minneapolis, MN). Fluo-4 AM NW, Fura-red, Syto 9, and propidium iodide were from Invitrogen (Stockholm, Sweden). Synthetic LL-37 was from Schafer-N (Copenhagen, Denmark).

Collection of lung tissue for histology and sputum. Lung tissue was obtained from five individuals undergoing lung transplantation for end-stage CF and eight previously lung healthy donors during surgery for lung cancer. The procedure was approved by the ethical review board (LU412-03). The clinical phenotype of the patients is shown in Supplementary Table 1 online. Sputum samples $(n=10)$ from CF patients were collected by the CF team at Skane University Hospital and this part of the study was approved by the ethical review board (2011/434). The representative sputum samples were collected during airway clearance therapies and processed to be used in experiments within $2 \mathrm{~h}$. All investigated patients were chronically colonized with $P$. aeruginosa.
Immunohistochemistry. Sections were single immunostained with EnVision Peroxidase/DAB Detection System kit (Rabbit/Mouse K5007; Dako, Glostrup, Denmark) detecting CXCL6 with affinitypurified rabbit polyclonal antibodies (Peprotech). In double immunostaining, DAB staining was followed by the detection of the second antibody against MPO (Dako) with Vina Green Chromogen kit (BRR807AH, Biocare Medical, Concord, CA) resulting in a green stain. The sections were incubated with Double Stain Blocking reagent (Dako). Isotype-matched control antibodies (Dako) were used as controls instead, replacing the primary antibodies at the same concentration. Staining of the tissues sections were performed identically and simultaneously using immunohistochemical robots (Autostainer; Dako). Sections were counterstained with Mayer's hematoxylin after completion of immunohistochemical staining. Apoptotic cells were detected using the TUNEL technique according to the manufacturer's instructions (ApopTag Fluorescein In Situ 
a
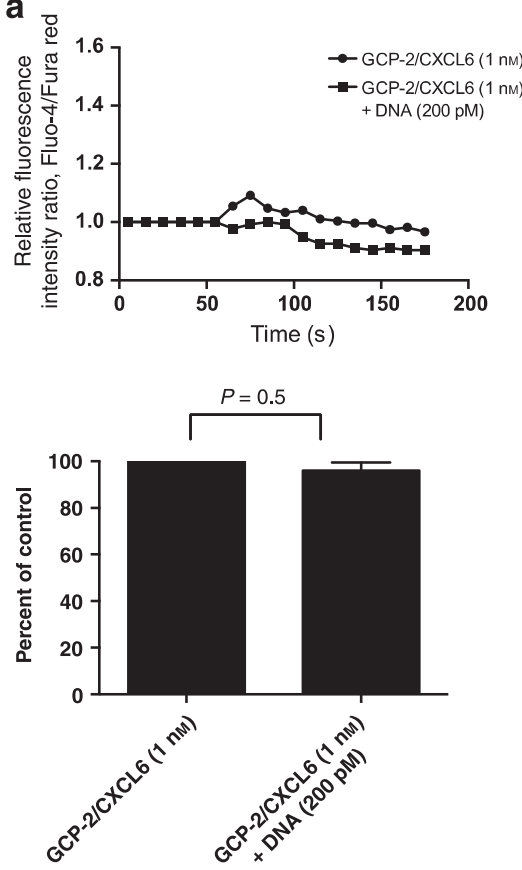
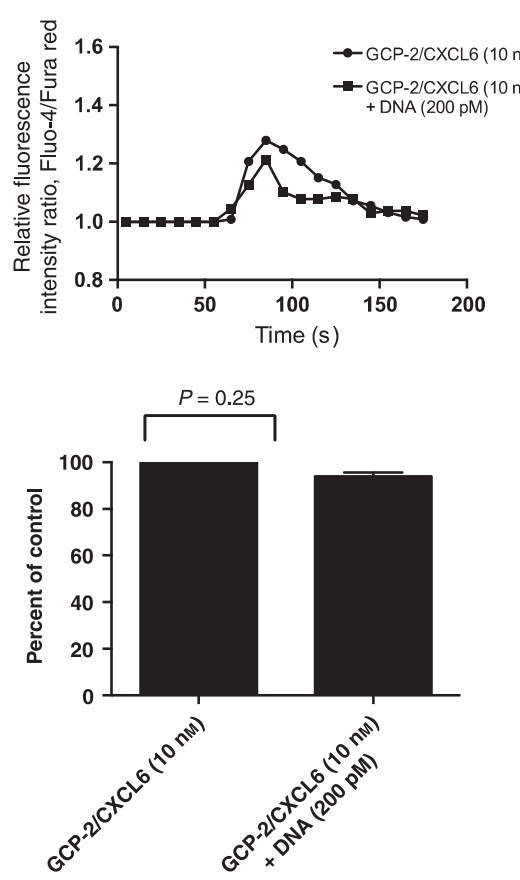
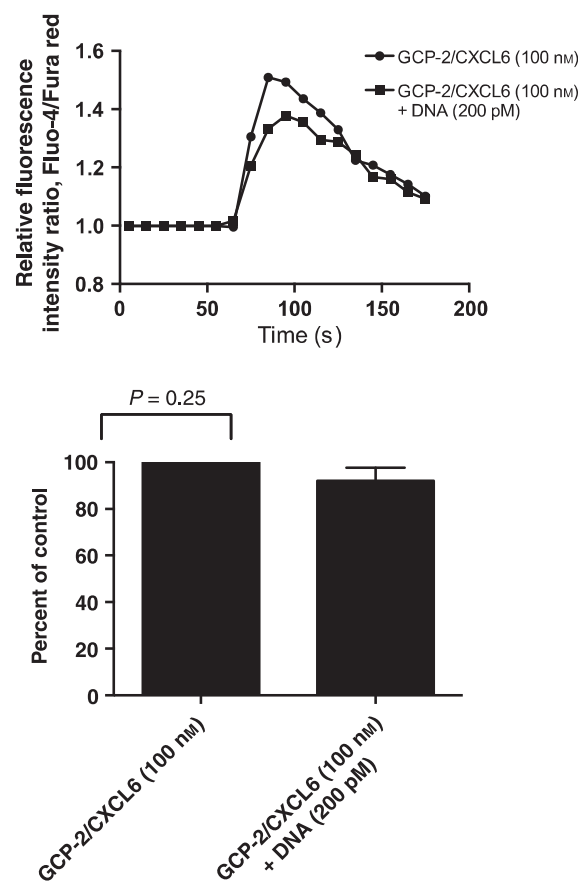
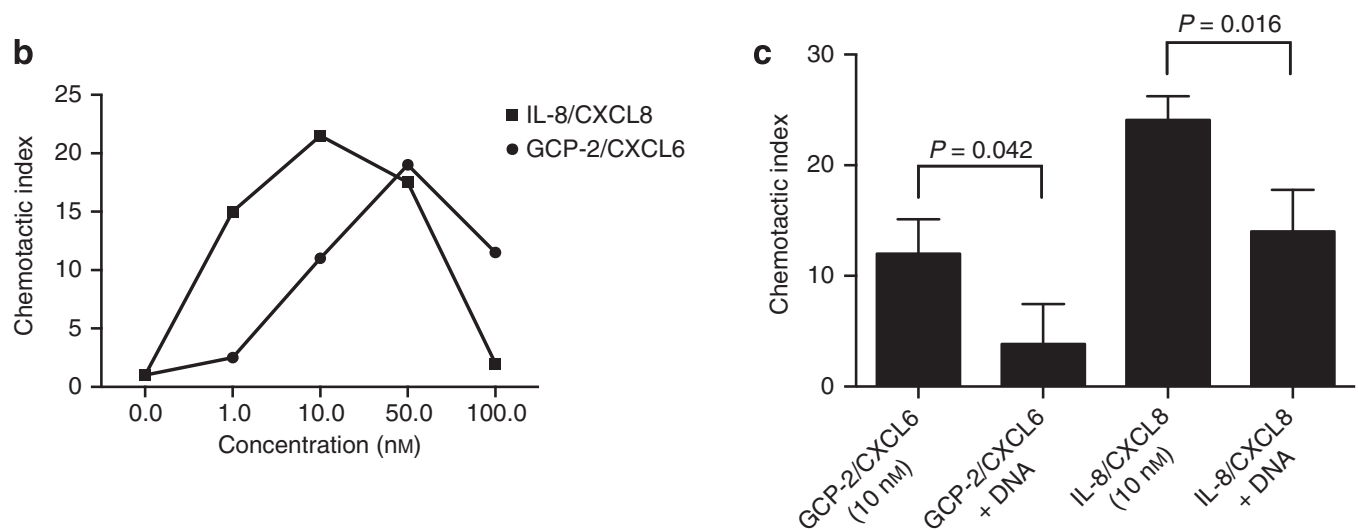

Figure 6 The neutrophil-activating but not the chemotactic properties of CXCL6 (chemokine (C-X-C motif) ligand 6) remains intact in the presence of DNA. (a) Dose-dependent calcium mobilization in neutrophils was detected reaching a plateau at a CXCL6 concentration of $100 \mathrm{~nm}$. Preincubation with DNA (at a final concentration of $200 \mathrm{pm}$ ) for $20 \mathrm{~min}$ had minor impact on the calcium mobilization response. Mean \pm s.d. of three separate experiments are shown where CXCL6 $(1,10$, and $100 \mathrm{~nm})$ is compared with CXCL6 in the presence of DNA (200 pM). The $P$-values were calculated using Wilcoxon $t$-test. (b) The chemotactic properties of CXCL6 and CXCL8 were investigated against neutrophils. Dose-dependent chemotaxis of CXCL6 and CXCL8 was obtained using concentrations ranging from 1 to $100 \mathrm{~nm}$. (c) Preincubation of the chemokines (both at $10 \mathrm{~nm}$ ) with DNA (200 pm) for $30 \mathrm{~min}$ before adding neutrophils significantly reduced the chemotactic properties of both chemokines. The results shown represent means and s.d. from three separate experiments and donors. The $P$-values were calculated using unpaired $t$-test.

Apoptosis Detection Kit, S7110; Merck Millipore, Billerica, MA). Briefly, tissue sections were deparaffinized and pretreated with proteinase K. Apoptotic cells were detected with sheep anti-digoxigenin fluorescein antibody. Neutrophils were detected using primary antibodies against MPO and secondary Alexa-555-conjugated goat anti-rabbit IgG antibodies (Invitrogen). Finally, the cell nuclei were stained with the double-stranded DNA marker Hoechst (H33342, Sigma-Aldrich, St Louis, MO). Sections were mounted in phosphatebuffered saline (PBS)/glycerine and visualized using a Nikon Eclipse $80 \mathrm{i}$ microscope (Nikon Instruments, Tokyo, Japan).

Immunoelectron microscopy. Tissue samples from CF lung explants obtained during transplantation or control tissue obtained during surgery for lung cancer were fixed in PBS containing $4 \%$ paraformaldehyde with $0.1 \%$ glutaraldehyde and prepared for immunostaining and transmission electron microscopy as previously described. ${ }^{51}$ In short, ultrathin sections were incubated with primary antibodies against CXCL6, in combination with either antibodies against BPI (a marker of azurophil granules; in-house antibodies) or hCAP-18 (a marker of specific granules; the antibodies were kindly provided by Dr Ole E Sørensen (Lund, Sweden)). This was followed by detection with secondary goat anti-rabbit antibodies or protein $\mathrm{A}$, separating the labeling as previously described (conjugated with 5 and $15 \mathrm{~nm}$ colloidal gold, respectively; Electron Microscopy Sciences, Fort Washington, MD). ${ }^{51}$ Specimens were examined in a JEOL JEM 1230 transmission electron microscope (JEOL, Peabody, MA) at $60 \mathrm{kV}$ accelerating voltage. Images were recorded with a Gatan Multiscan 791 CCD camera (Pleasanton, CA). 
a
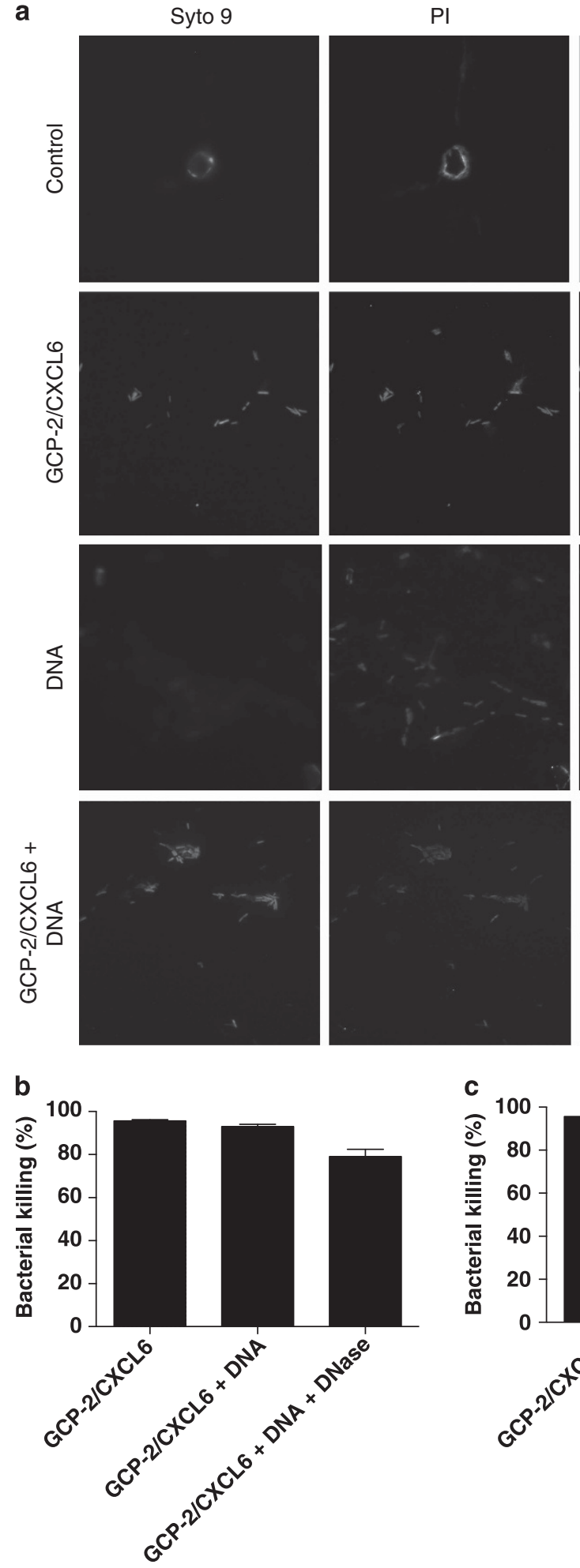

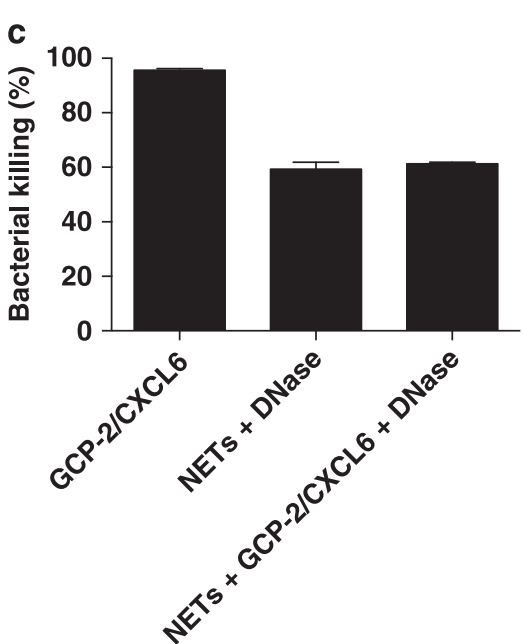

Figure 7 The bactericidal activity of CXCL6 (chemokine (C-X-C motif) ligand 6) is not affected by DNA. (a) Fluorescent dyes (Syto 9 (green) staining all bacteria and propidium iodide ( $\mathrm{PI}$, red) binding intracellular DNA in killed bacteria) were used to assess bacterial viability. In the overlap, green staining indicate live bacteria, whereas red/yellow staining indicate dead or damaged bacteria, being labeled by both dyes. The top row shows bacteria ( $P$ seudomonas aeruginosa) in buffer alone, mainly stained green (live bacteria). The second row shows bacteria subjected to granulocyte chemotactic protein 2 (GCP-2; $1 \mu \mathrm{M}$ ), the bacteria appearing yellow, indicating dead/damaged bacteria. The third row shows bacteria subjected to DNA (200 pм) alone; the bacteria are green, an indication of intact bacteria. The fourth row shows bacteria subjected to GCP-2 $(1 \mu \mathrm{M})$ that have been preincubated with DNA (200 pM), the bacteria appearing red, thus indicating dead or damaged bacteria. No differences were observed in the killing of $P$. aeruginosa with CXCL6 alone or when the chemokine was preincubated with DNA and used in the viable count assay. (b) Addition of DNAse $\left(5 \mathrm{U} \mathrm{ml}^{-1}\right)$ to bacteria incubated with a combination of CXCL6 and DNA, possibly releasing bacteria trapped in DNA, did not significantly affect the results obtained in the viable counts assay. (c) Purified neutrophil extracellular traps (NETs) and CXCL6 bound to NETs killed $\sim 60 \%$ of the bacteria. A full color version of this figure is available at the Mucosal Immunology journal online. 
Bactericidal assay. P. aeruginosa (strain PA01) and the nonmucoid clinical isolates (195b, 022A, and 023 from the Department of Clinical Microbiology in Lund, Sweden) were cultured in Todd Hewitt broth at $37^{\circ} \mathrm{C}$ under aerobic conditions to mid-exponential growth phase $\left(\mathrm{OD}_{620} \approx 0.4\right)$, diluted to a $1 \%$ bacterial concentration $\left(2 \times 10^{9}\right.$ colonyforming units (CFUs) per $\mathrm{ml}$ ), washed in incubation buffer $(10 \mathrm{~mm}$ Tris/ $\mathrm{HCl}, 5 \mathrm{mM}$ glucose; standard $\mathrm{pH} 7.4$ and 7.0 was produced by addition of $\mathrm{HCl}$ ), and adjusted to a concentration of $2 \times 10^{6}$ CFUs per ml. Then, $40 \mu \mathrm{l}$ of the bacterial solution $\left(10^{5} \mathrm{CFUs}\right)$ was incubated in buffer alone or with various concentrations of the indicated protein or mixtures for $1 \mathrm{~h}$ at $37^{\circ} \mathrm{C}$. To quantify the bactericidal activity, serial dilutions in incubation buffer were plated on $\mathrm{TH}$-agar in duplicates and incubated overnight at $37^{\circ} \mathrm{C}$. The percent bacterial killing was calculated by comparison with the number of CFUs when incubated in buffer alone.

Sodium dodecyl sulfate-polyacrylamide gel electrophoresis/ proteases. Recombinant human CXCL6, CXCL8, and CXCL9 (5 $\mu \mathrm{g}$ each) were preincubated with neutrophilic elastase (Calbiochem, Darmstadt, Germany) or P. aeruginosa elastase ( $0.5 \mu$ g each; Sigma (St Louis, MO) for 3 and $18 \mathrm{~h}$ at $37^{\circ} \mathrm{C}$ or preincubated with DNA (500 ng) for $1 \mathrm{~h}$ and then coincubated with neutrophil elastase for $18 \mathrm{~h}$ at $37^{\circ} \mathrm{C}$. This was followed by separation on Tris-tricine gels. Coomassie Brilliant Blue R-350 (Sigma-Aldrich) was used to visualize the proteins. Western blot was performed to detect CXCL6 in neutrophil lysates and NETs. Possible binding of exogenous CXCL6 added to the NETs was also investigated using this method.

Purification of neutrophils. Peripheral neutrophils were purified from healthy individuals using Polymorphprep (Axis-Shield, Oslo, Norway) according to the manufacturer's instructions. ${ }^{52}$ The preparations contained $>96 \%$ of neutrophils. For negative staining, the cells were washed and diluted in ME-Medium (Invitrogen) supplemented with HEPES buffer (Sigma-Aldrich). For calcium mobilization, the cells were diluted in PBS supplemented with 1\% fetal bovine serum (Invitrogen), and for chemotaxis the cells were diluted in Hanks' balanced salt solution (Invitrogen) supplemented with $1 \%$ fetal bovine serum. The neutrophil lysates were obtained by five freeze/thaw cycles in PBS at $5 \times 10^{6}$ neutrophils per $\mathrm{ml}$, followed by centrifugation to remove cellular debris.

Induction of NETs to investigate possible binding of CXCL6. NETs were induced by incubating neutrophils with phorbol 12-myristate 13acetate at $50 \mathrm{ng} \mathrm{ml}^{-1}$ (Sigma-Aldrich) for $2 \mathrm{~h}$ at $37^{\circ} \mathrm{C}$. To investigate possible binding of CXCL6 to NETs, either PBS alone or $2.5 \mu \mathrm{g}$ of CXCL6 was added to the suspension containing NETs (corresponding to $5 \times 10^{5}$ neutrophils in total) for $1 \mathrm{~h}$ at $37^{\circ} \mathrm{C}$. The NET suspension was washed twice with PBS and boiled in sodium dodecyl sulfate-dithiothreitol sample buffer, followed by sodium dodecyl sulfate-polyacrylamide gel electrophoresis and western blot. In viable count assays, NETs were incubated with PBS alone or CXCL6 (5 mg), followed by washing and incubation with bacteria (PA01) for $1 \mathrm{~h}$ at $37^{\circ} \mathrm{C}$. Thereafter, the samples were incubated with DNase $\left(5 \mathrm{U} \mathrm{ml}^{-1}\right)$ for $20 \mathrm{~min}$ at $37^{\circ} \mathrm{C}$. To quantify the bactericidal activity, serial dilutions in incubation buffer were plated on TH agar in duplicates and incubated overnight at $37^{\circ} \mathrm{C}$. The percent bacterial killing was calculated by comparison with the number of CFUs obtained when incubated in buffer alone.

Negative staining and transmission electron microscopy. Neutrophils isolated from peripheral blood of healthy individuals as described above were seeded on poly-lysine-treated slides and activated with $100 \mathrm{mU} \mathrm{ml}^{-1}$ glucose oxidase for $60 \mathrm{~min}$. Both neutrophils and sputum mobilized from CF airways were fixed in $2.5 \%(\mathrm{v} / \mathrm{v})$ glutaraldehyde and processed for negative staining using $0.75 \%$ uranyl formate, and examined by electron microscopy using JEOL (Tokyo, Japan) 1200EX transmission electron microscope operated at $60 \mathrm{kV}$ accelerating voltage as described earlier. ${ }^{53}$

Experimental DNA. The DNA used for gel shift assays, viable counts assay, calcium mobilization, and chemotaxis experiments originated from the plasmid pCR2.1-TOPO (3,900 base pairs (bp); Invitrogen). Digestion with SphI (Thermo Scientific, Göteborg, Sweden) released a fragment of 1,509 bp (GC content 55.5\%). The fragment was separated by electrophoresis on a $1 \%$ agarose gel in $1 \times$ tris-acetate-EDTA (TAE) buffer containing SYBR Safe DNA gel stain (Life Technologies, Carlsbad, CA) diluted 1:10,000. QIAquick Gel Extraction kit (Qiagen, Düsseldorf, Germany) was used to purify the fragment from the gel. The DNA was pooled and concentration determined by spectrophotometry (Nanodrop; Thermo Scientific). The sequence of the biotinylated DNA used in surface plasmon resonance experiments was Biotin-C6 5' -AACCCGTAGAACTTCCTAACTGTAATTTAG-3' (a randomly selected sequence from the human arylesterase 1 precursor gene; GC content 37\%; DNA Technology, Århus, Denmark).

Electrophoretic mobility shift assay. The $1.5 \mathrm{kbp}$ DNA fragment $(200 \mathrm{ng})$ alone or preincubated with increasing amounts of CXCL6 (6.3-50 pmol) for $15 \mathrm{~min}$ at $37^{\circ} \mathrm{C}$ was subjected to electrophoresis in a $1 \%$ agarose gel in TAE buffer and visualized by SYBR safe at different time points to investigating retardation of DNA migration using the Bio-Rad Chemidoc system (Bio-Rad, Hercules, CA).

Surface plasmon resonance spectrometry. Sensor chip SA (carboxymethylated dextran preimmobilized with streptavidin; GE Healthcare, Uppsala, Sweden) was used for immobilization of biotinylated DNA. The immobilization levels were 1,300 resonance units. A flow cell subjected to the coupling reaction without added DNA biotin was used as a control for bulk refraction index changes. For affinity measurements, binding and dissociation were monitored in a Biacore X100 instrument (GE Healthcare). Different concentrations of CXCL6, CXCL8, and CCL3 (62.5-1000 nM) were injected over the coated surface at a flow rate of $30 \mu \mathrm{l} \mathrm{min}{ }^{-1}$ and a temperature of $25^{\circ} \mathrm{C}$ using a running buffer containing $10 \mathrm{~mm}$ Hepes, $150 \mathrm{~mm} \mathrm{NaCl}, 0.005 \%$ surfactant P20, and $3.4 \mathrm{~mm}$ EDTA ( $\mathrm{pH}$ 7.5). Regeneration was performed with a $50 \mathrm{~mm}$ sodium hydroxide solution. The data were fitted to 1:1 binding model.

Measurement of calcium mobilization. Calcium mobilization was measured as a ratio between Fluo-4 AM NW and Fura-red by FACS (BD LSR II flow cytometer; BD, Stockholm, Sweden). Briefly, $1 \times 10^{7}$ cells per ml were loaded with 3 and $6 \mu \mathrm{M}$ Fluo- 4 AM or Fura-red respectively for $45 \mathrm{~min}$ at $37^{\circ} \mathrm{C}$. The neutrophils were then kept on ice and prewarmed to $37^{\circ} \mathrm{C}$ before acquiring data. The cells were analyzed for intracellular calcium release after addition of CXCL6 (1-100 nM), either alone or after preincubation with DNA (200 pM).

Chemotaxis assay. Chemotaxis of purified neutrophils was quantified using a Transwell system (polycarbonate filters with pore size $5 \mu \mathrm{m})$. Briefly, neutrophils were placed in the top well in a total volume of $100 \mu \mathrm{l}$, and medium alone or CXCL6 and CXCL8 (1-100 nM) were added to the bottom well. The plates were incubated for $4 \mathrm{~h}$ in a humidified incubator at $37^{\circ} \mathrm{C}$ with $5 \% \mathrm{CO}_{2}$. Cells that have migrated to the bottom well were stained with Tryphan blue (0.4\%) and the density was determined using a hemacytometer.

Fluorescence microscopy. P. aeruginosa PA01 was cultured in Todd Hewitt broth at $37^{\circ} \mathrm{C}$ under aerobic conditions to mid-exponential growth phase $\left(\mathrm{OD}_{620} \approx 0.4\right)$, diluted to a $1 \%$ bacterial concentration $\left(2 \times 10^{9} \mathrm{CFUs}\right.$ per $\left.\mathrm{ml}\right)$, washed in incubation buffer $(10 \mathrm{~mm}$ Tris/HCl, $5 \mathrm{~mm}$ glucose, $\mathrm{pH} 7.4$ ), and adjusted to a concentration of $1 \times 10^{7} \mathrm{CFUs}$ per ml. Bacterial suspension $(60 \mu \mathrm{l})$ was incubated with CXCL6 (final concentration $12.5 \mu \mathrm{M}$ ) alone or with previously preincubated CXCL6 (final concentration $12.5 \mu \mathrm{M}$ ) with DNA (final concentration $25.2 \mathrm{nM}$ ) for $20 \mathrm{~min}$, and for $1 \mathrm{~h}$ in a humidified incubator at $37^{\circ} \mathrm{C}$ with $5 \% \mathrm{CO}_{2}$. Thereafter, the live/dead staining, $150 \mu \mathrm{l} \mathrm{SYTO} 9(5 \mu \mathrm{M})$ and propidium iodide $(30 \mu \mathrm{M})$ were added to the incubations for $20 \mathrm{~min}$ in the dark, washed in PBS, added to previously poly-L-lysine-coated coverslips, fixed with $1 \%$ paraformaldehyde, and embedded in mounting media overnight. Images were acquired using a Nikon Eclipse TE200 equipped with a Hamamatsu C4742-95 CCD camera, 
using Plan Apochromat $20 \times$ and $100 \times$ objectives. NIS-elements 3.1 (Nikon) software was used for image acquisition and processing. The bacterial concentration was scaled up 12.5 times to get enough bacteria for the experiment, and as a result the CXCL6 and DNA concentrations were also scaled up 12.5 times.

SUPPLEMENTARY MATERIAL is linked to the online version of the paper at http://www.nature.com/mi

\section{ACKNOWLEDGMENTS}

The help of Mattias Collin and Julia Garbe concerning DNA methodology and reagents is greatly appreciated. We thank Pia Andersson and Maria Baumgarten for excellent technical assistance. We also express our gratitude to the CF team at Skåne University Hospital, Lund, for collecting sputa. This work was supported by grants from the Swedish Research Council (project A0615601 HML and 4224 AE), the Swedish Heart and Lung Foundation (project 20100164), the Swedish Foundation for Strategic Research, the Swedish Government Funds for Clinical Research (ALF), Swedish Society for Medical Research, and the foundations of Bergh, Greta and Johan Kock, and Alfred Österlund.

\section{DISCLOSURE}

The authors declared no conflict of interest.

(c) 2016 Society for Mucosal Immunology

\section{REFERENCES}

1. O'Sullivan, B.P. \& Freedman, S.D. Cystic fibrosis. Lancet 373, 1891-1904 (2009).

2. Chen, J.-H. et al. Loss of anion transport without increased sodium absorption characterizes newborn porcine cystic fibrosis airway epithelia. Cell 143, 911-923 (2010).

3. Gilljam, H., Ellin, A. \& Strandvik, B. Increased bronchial chloride concentration in cystic fibrosis. Scand. J. Clin. Lab. Invest. 49, 121124 (1989).

4. Joris, L., Dab, I. \& Quinton, P.M. Elemental composition of human airway surface fluid in healthy and diseased airways. Am. Rev. Respir. Dis. 148, 1633-1637 (1993).

5. Pezzulo, A.A. et al. Reduced airway surface $\mathrm{pH}$ impairs bacterial killing in the porcine cystic fibrosis lung. Nature 487, 109-113 (2012).

6. Smith, J.J., Travis, S.M., Greenberg, E.P. \& Welsh, M.J. Cystic fibrosis airway epithelia fail to kill bacteria because of abnormal airway surface fluid. Cell 85, 229-236 (1996).

7. Fahy, J.V. \& Dickey, B.F. Airway mucus function and dysfunction. N. Engl. J. Med. 363, 2233-2247 (2010)

8. Voynow, J.A. \& Rubin, B.K. Mucins, mucus, and sputum. Chest 135, 505512 (2009).

9. Henke, M.O., Renner, A., Huber, R.M., Seeds, M.C. \& Rubin, B.K. MUC5AC and MUC5B mucins are decreased in cystic fibrosis airway secretions. Am. J. Respir. Cell Mol. Biol. 31, 86-91 (2004).

10. Kater, A., Henke, M.O. \& Rubin, B.K. The role of DNA and actin polymers on the polymer structure and rheology of cystic fibrosis sputum and depolymerization by gelsolin or thymosin beta 4. Ann. NY Acad. Sci. 1112, 140-153 (2007)

11. Potter, J.L., Spector, S., Matthews, L.W. \& Lemm, J. Studies on pulmonary secretions. 3. The nucleic acids in whole pulmonary secretions from patients with cystic fibrosis, bronchiectasis, and laryngectomy. Am. Rev. Respir. Dis. 99, 909-916 (1969).

12. Hartl, D. et al. Innate immunity in cystic fibrosis lung disease. J. Cyst. Fibros. 11, 363-382 (2012).

13. Bianchi, S.M. etal. Impairment of apoptotic cell engulfment by pyocyanin, a toxic metabolite of Pseudomonas aeruginosa. Am. J. Respir. Crit. Care Med. 177, 35-43 (2008).

14. McKeon, D.J. et al. Prolonged survival of neutrophils from patients with Delta F508 CFTR mutations. Thorax 63, 660-661 (2008).

15. Moriceau, S. et al. Coronin-1 is associated with neutrophil survival and is cleaved during apoptosis: potential implication in neutrophils from cystic fibrosis patients. J. Immunol. 182, 7254-7263 (2009).
16. Usher, L.R. et al. Induction of neutrophil apoptosis by the Pseudomonas aeruginosa exotoxin pyocyanin: a potential mechanism of persistent infection. J. Immunol. 168, 1861-1868 (2002).

17. Vandivier, R.W. et al. Elastase-mediated phosphatidylserine receptor cleavage impairs apoptotic cell clearance in cystic fibrosis and bronchiectasis. J. Clin. Invest. 109, 661-670 (2002).

18. Brinkmann, V. et al. Neutrophil extracellular traps kill bacteria. Science $\mathbf{3 0 3 ,}$ 1532-1535 (2004).

19. Manzenreiter, R. et al. Ultrastructural characterization of cystic fibrosis sputum using atomic force and scanning electron microscopy. J. Cyst. Fibros. 11, 84-92 (2012).

20. Urban, C.F. et al. Neutrophil extracellular traps contain calprotectin, a cytosolic protein complex involved in host defense against Candida albicans. PLoS Pathog. 5, e1000639 (2009).

21. Proost, P. et al. Identification of a novel granulocyte chemotactic protein (GCP-2) from human tumor cells. In vitro and in vivo comparison with natural forms of GRO, IP-10, and IL-8. J. Immunol. 150, 1000-1010 (1993).

22. Proost, P. et al. Human and bovine granulocyte chemotactic protein-2: complete amino acid sequence and functional characterization as chemokines. Biochemistry 32, 10170-10177 (1993).

23. Wuyts, A. et al. Characterization of synthetic human granulocyte chemotactic protein 2: usage of chemokine receptors CXCR1 and CXCR2 and in vivo inflammatory properties. Biochemistry 36, 27162723 (1997).

24. Yang, D. et al. Many chemokines including CCL20/MIP-3alpha display antimicrobial activity. J. Leukoc. Biol. 74, 448-455 (2003).

25. Linge, H.M. et al. The human CXC chemokine granulocyte chemotactic protein 2 (GCP-2)/CXCL6 possesses membrane-disrupting properties and is antibacterial. Antimicrob. Agents Chemother. 52, 2599-2607 (2008).

26. Jovic, S. et al. Expression of MIG/CXCL9 in cystic fibrosis and modulation of its activities by elastase of Pseudomonas aeruginosa. J. Innate Immun. 6, 846-859 (2014).

27. Halverson, T.W.R., Wilton, M., Poon, K.K.H., Petri, B. \& Lewenza, S. DNA is an antimicrobial component of neutrophil extracellular traps. PLOS Pathog. 11, e1004593 (2015).

28. Osika, E. et al. Distinct sputum cytokine profiles in cystic fibrosis and other chronic inflammatory airway disease. Eur. Respir. J. 14, 339-346 (1999).

29. Prause, O., Laan, M., Lötvall, J. \& Lindén, A. Pharmacological modulation of interleukin-17-induced GCP-2-, GRO-alpha- and interleukin-8 release in human bronchial epithelial cells. Eur. J. Pharmacol. 462, 193-198 (2003).

30. Van Damme, J. et al. Granulocyte chemotactic protein-2 and related CXC chemokines: from gene regulation to receptor usage. J. Leukoc. Biol. 62 , 563-569 (1997).

31. Wuyts, A. et al. The CXC chemokine GCP-2/CXCL6 is predominantly induced in mesenchymal cells by interleukin-1 beta and is down-regulated by interferon-gamma: comparison with interleukin-8/CXCL8. Lab. Invest. 83, 23-34 (2003).

32. Dubin, P.J. \& Kolls, J.K. IL-23 mediates inflammatory responses to mucoid Pseudomonas aeruginosa lung infection in mice. Am. J. Physiol. Lung Cell Mol. Physiol 292, L519-L528 (2007).

33. Tan, H.L. et al. The Th17 pathway in cystic fibrosis lung disease. Am. J. Respir. Crit. Care Med. 184, 252-258 (2011).

34. Tiringer, K. et al. ATh17- and Th2-skewed cytokine profile in cystic fibrosis lungs represents a potential risk factor for Pseudomonas aeruginosa infection. Am. J. Respir. Crit. Care Med. 187, 621-629 (2013).

35. Nakamura, H., Yoshimura, K., McElvaney, N.G. \& Crystal, R.G. Neutrophil elastase in respiratory epithelial lining fluid of individuals with cystic fibrosis induces interleukin-8 gene expression in a human bronchial epithelial cell line. J. Clin. Invest. 89, 1478-1484 (1992).

36. Theilgaard-Mönch, $\mathrm{K}$. et al. The transcriptional program of terminal granulocytic differentiation. Blood 105, 1785-1796 (2005).

37. Hager, M., Cowland, J.B. \& Borregaard, N. Neutrophil granules in health and disease. J. Intern. Med. 268, 25-34 (2010).

38. Fittschen, C. \& Henson, P.M. Linkage of azurophil granule secretion in neutrophils to chloride-ion transport and endosomal transcytosis. J. Clin. Invest. 93, 247-255 (1994).

39. Besnard, A.-G. et al. CXCL6 antibody neutralization prevents lung inflammation and fibrosis in mice in the bleomycin model. J. Leukoc. Biol. 94, 1317-1323 (2013). 
40. Bozic, C.R., Gerard, N.P. \& Gerard, C. Receptor binding specificity and pulmonary gene expression of the neutrophil-activating peptide ENA-78. Am. J. Respir. Cell Mol. Biol. 14, 302-308 (1996).

41. Wyatt, H.A., Sampson, A.P., Balfour-Lynn, I.M. \& Price, J.F. Production of the potent neutrophil chemokine, growth-related protein alpha (GROalpha), is not elevated in cystic fibrosis children. Respir. Med. 94, 106-111 (2000).

42. Scapini, P. et al. The neutrophil as a cellular source of chemokines. Immunol. Rev. 177, 195-203 (2000).

43. Kuschert, G.S. et al. Glycosaminoglycans interact selectively with chemokines and modulate receptor binding and cellular responses. Biochemistry 38, 12959-12968 (1999).

44. Rot, A. Neutrophil attractant/activation protein-1 (interleukin-8) induces in vitro neutrophil migration by haptotactic mechanism. Eur. J. Immunol. 23, 303-306 (1993)

45. Hoogewerf, A.J. et al. Glycosaminoglycans mediate cell surface oligomerization of chemokines. Biochemistry 36, 13570-13578 (1997).

46. Nordin, S.L. et al. High expression of midkine in the airways of patients with cystic fibrosis. Am. J. Respir. Cell Mol. Biol. 49, 935-942 (2013).
47. Menegazzi, R., Decleva, E. \& Dri, P. Killing by neutrophil extracellular traps: fact or folklore? Blood 119, 1214-1216 (2012).

48. Rubin, B.K., Kater, A.P. \& Goldstein, A.L. Thymosin beta4 sequesters actin in cystic fibrosis sputum and decreases sputum cohesivity in vitro. Chest 130, 1433-1440 (2006).

49. Suri, R. The use of human deoxyribonuclease (rhDNase) in the management of cystic fibrosis. BioDrugs 19, 135-144 (2005).

50. Dubois, A.V. et al. Poly-L-Lysine compacts DNA, kills bacteria, and improves protease inhibition in cystic fibrosis sputum. Am. J. Respir. Crit. Care Med. 188, 703-709 (2013).

51. Rohde, M. et al. Localization of membrane-associated (NiFe) and (NiFeSe) hydrogenases of Desulfovibrio vulgaris using immunoelectron microscopic procedures. Eur. J. Biochem. 191, 389-396 (1990).

52. Christenson, K., Björkman, L., Karlsson, A. \& Bylund, J. Regulation of neutrophil apoptosis differs after in vivo transmigration to skin chambers and synovial fluid: a role for inflammasome-dependent interleukin- $1 \beta$ release. J. Innate Immun. 5, 377-388 (2013).

53. Oehmcke, S., Mörgelin, M. \& Herwald, H. Activation of the human contact system on neutrophil extracellular traps. J. Innate Immun. 1, 225-230 (2009). 